\title{
A Diagnostic Scoring System to Distinguish Precocious Puberty from Premature Thelarche based on Clinical and Laboratory Findings
}

\author{
Murat Karaoglan, ${ }^{1,}{ }^{*}$ Mehmet Keskin, ${ }^{1}$ Seval Kul, ${ }^{2}$ and Ayhan Ozkur ${ }^{3}$ \\ ${ }^{1}$ Gaziantep University Faculty of Medicine, Pediatric Endocrinology, Gaziantep, Turkey \\ ${ }^{2}$ Division of Biostatistics, Gaziantep University Faculty of Medicine, Gaziantep, Turkey \\ ${ }^{3}$ Radiology Department, Gaziantep University Faculty of Medicine, Gaziantep, Turkey \\ "Corresponding author: Murat Karaoglan, Department of Pediatric Endocrinology, Gaziantep University Faculty of Medicine, Gaziantep, Turkey. Tel: +90-05324091616, E-mail: \\ muratkaraoglan@hotmail.com
}

Received 2017 November 16; Revised 2018 February 01; Accepted 2018 March 02.

\begin{abstract}
Background: The diagnosis of patients who present with early pubertal signs can pose a challenge.

Objectives: The aim of this study was to design a new diagnostic scoring system based on clinical and laboratory findings to distinguish precocious puberty (PP) from premature thelarche (PT) among girls diagnosed with early puberty.

Methods: We enrolled 267 girls (PP, $n=164 ;$ PT, $n=103$ ) previously diagnosed with early puberty using GnRH test, retrospectively. A diagnostic scoring model $(\mathrm{M})$ was constructed with five variables and their cut off values were determined for scoring: age of onset (6.5 years), bone age (BA)/choronologic age (CA) ratio ( $\geq 1.1$ ), estradiol (12 pg/ml), uterine length (32 $\mathrm{mm}$ ) and ovarian volume (1.09 $\mathrm{cm}^{3}$ ). Overall score was determined for model. The model was also applied prospectively to a second girls population $(\mathrm{n}=86)$ that showed signs of early puberty.

Results: The sensitivity and specificity of model was $89.6 \%$ and $87.4 \%$, respectively. In the cohort group, the sensitivity and specificity of model was $90 \%$ and $89.4 \%$, prospectively.

Conclusions: A diagnostic scoring system, based on clinical and laboratory findings can be an alternative or complementary method for the differential diagnosis of early puberty.
\end{abstract}

Keywords: Early Puberty, Precocious Puberty, Premature Thelarche, Scoring

\section{Background}

The differential diagnosis of precocious puberty (PP) from premature thelarche (PT) and its variants sometimes poses (1). The clinical findings and tests have various drawbacks, and none of the tests alone can identify early pubertal disorders (2). The gonadotropin releasing hormone (GnRH) stimulation test is considered the gold standard. However, it is expensive, time consuming, painful and invasive, resulting in patient discomfort. Furthermore, studies have reported different specificity, sensitivity and cutoff values for $\mathrm{GnRH}(3,4)$. Many factors, including the specificities of follicle stimulating hormone (FSH) and luteinizing hormone (LH) assays, influence GnRH test results (5). Estradiol measurements are less reliable indicators of the stage of puberty (2). In addition, estradiol levels sometimes fluctuate because of the pulsatile secretion of gonadotropin, which stimulates ovarian cysts (6). Since the pubertal process may stall or regress and be reactivated at a later point, breast development is not always reliable in- dicator of the pubertal status $(7,8)$. The differential diagnosis is particularly challenging in patients who fall into grey zone category (9).

Pelvic ultrasound has been shown to be an efficient tool in distinguishing PP from PT, particularly when the results of the GnRH stimulation test are equivocal. A number of studies concluded that pelvic ultrasound may provide an earlier clinical indication of PP than pubertal GnRH test results $(10,11)$.

Scoring systems are commonly used to diagnose or predict progress in many diseases and also provide a simple and systematic approach for inexperienced junior staff clinicians $(12,13)$. A diagnostic scoring system could contribute to distinguish equivocal cases of PP and PT and also provide a simpler alternative to current methods for use by clinicians who are faced with making decisions on cases of early puberty. Thus far, no scoring system for use in cases of PP and PT or its variants has been developed. 


\section{Objectives}

The aim of the present study was to establish a new simple, fast, useful and cost-effective scoring system based on clinical and laboratory findings to distinguish PP from PT and its variants as an alternative or complementary approach to the GnRH test.

\section{Methods}

The first part of this study was performed as a retrospective case-control study to build scoring model and also its second part was applied as prospective cohort study to validate model. Study consisted of 267 girls previously diagnosed with PP or PT according to conventional diagnosis protocol (including GnRH test) of early puberty in 2010 - 2014. All girls with PP were diagnosed as idiopathic. The girls, diagnosed with secondary PP were not included into the study. Retrospective medical records of all girls were used to construct a new scoring model. The inclusion criteria comprized all girls aged $<8$ years who had breast development classified as at least B2 according to the Tanner stage. This study was approved by Gaziantep University Clinical Research Ethic Committee (No, 26.5.2014/186). Informed consents were provided by all the children's parents.

All girls were previously diagnosed according to following conventional applications:

Breast development was defined by the diameter of palpable glandular tissue (diameter of at least $1 \mathrm{~cm}$ ) when holding the breast. Growth percentile charts for Turkish children were used to calculate height and weight standard deviation scores (SDSs) $(14,15)$. An increase of at least $6 \mathrm{~cm}$ in height in the last year was accepted as an accelerated growth rate. Growth velocity could not be calculated in some girls $(n=52)$ due to the absence of growth records within the previous six months. In these cases, height in the 90th percentile or greater was used instead of growth velocity (16). LH levels $<0.3 \mathrm{IU} / \mathrm{L}$ were considered prepubertal, as described by Neely et al, and levels $>0.3 \mathrm{IU} / \mathrm{L}$ were considered pubertal (17).

The following criteria were previously considered to denote conventional pubertal findings in practice: a) growth velocity of at least $6 \mathrm{~cm} /$ last year or height in at least the 90th percentile (if there were no growth records); b) at least B2 on the Tanner stage of breast development; c) $\mathrm{BA} / \mathrm{CA}$ ratio $\geq 1, \mathrm{~d}$ ) mean ovarian volume of at least 1 $\mathrm{cm}^{3}$, e) uterine length of at least $35 \mathrm{~mm}$; and f) baseline $\mathrm{LH}$ $(\mathrm{bLH})>0.3 \mathrm{UI} / \mathrm{L}$, peak LH $(\mathrm{pLH})>5 \mathrm{UI} / \mathrm{L}$, stimulated LH/FSH $(\mathrm{sLH} / \mathrm{FSH})$ ratio $>0.3$ or estradiol $>12 \mathrm{pg} / \mathrm{ml}(17-20)$. The patients were classified into two groups: PP and PT. PT referred to the isolated appearance of breast budding, with- out any pubertal finding before the age of 8 years. PP referred to breast development in girls younger than 8 years, together with the presence of any pubertal finding, including gonadotropin activation and bLH $>0.3 \mathrm{UI} / \mathrm{L}, \mathrm{pLH}>5$ $\mathrm{UI} / \mathrm{L}$ or $\mathrm{SLH} / \mathrm{FSH}$ ratio $>0.3$.

Breast development stage was assessed according to the Tanner stage. Height was measured using a wallmounted stadiometer (Harpenden, Haltein, UK). The BMI SDSs were calculated based on available data on Turkish children (21). The radiological determination of BA was interpreted according to Greulich and Pyle.

The GnRH stimulation test was just performed to diagnose in 210 girls (PP, $\mathrm{n}=137 ; \mathrm{PT}, \mathrm{n}=73$ ). LH and FSH assays were performed at baseline and 30 and 60 min after intravenous administration of a standard dose $\left(100 \mu \mathrm{g} / \mathrm{m}^{2}\right)$ of GnRH (LH-RH Ferring, Ferring, Switzerland). This test was not performed in cases of bLH $>1 \mathrm{IU} / \mathrm{L}(\mathrm{n}=37)$, because this level is accepted to diagnose with PP.GnRH test was performed in all cases in whom any pubertal finding was present. The GnRH test was performed for differential diagnosis in all 73 girls in the PT group. In the cohort group $(n=86)$, the test was performed in just 17 girls.

All blood tests were drawn at $09 \mathrm{am}$. LH, FSH, estradiol and FSH levels were measured in all the girls. LH and FSH levels were determined using an electrochemiluminescence immunoassay, with a Cobas@6000 (Roche Diagnostic, Manheim, Germany) analyzer. The sensitivity of the analyzer for $\mathrm{LH}$ and FSH was $0.1 \mathrm{IU} / \mathrm{L}$ and $0.1 \mathrm{IU} / \mathrm{L}$, respectively.

Pelvic ultrasound scans were performed in all cases using a linear VF13-5 (13.5 MHz) transducer and Siemens Sonoline Antares ultrasound machine (Siemens Medical Solutions USA Inc., Malvern, PA). The same radiologist (A.O.) performed all the scans. The following parameters were measured: a) uterine length, transverse diameter (width) and fundal anteroposterior diameter and b) ovarian height, width and length. The uterine and ovarian volumes were calculated using the formula for ellipsoid bodies (V: longitudinal diameter $\times$ transverse diameter $\times$ anterioposterior $\times 0.5233$ ).

All the girls diagnosed with PP underwent cranial MRI. Any cranial pathology (e.g. hamartomas, adenomas or hydrocephalus) that could be a potential cause of PP was recorded. The shape and any heterogenic opacification of the pituitary gland was noted.

The predictive variables used in the differential diagnosis were as follows: age at diagnosis, BA, growth velocity or height, weight, body mass index (BMI), bLH level, stimulated LH/FSH (sLH/FSH) level, peak LH (pLH) level, estradiol level, DHEA-S, additional disease, cranial/pituitary pathology, uterine length and ovarian volume. 


\subsection{Statistical Analysis}

The normality of distribution of continuous variables was tested by Shaphiro Wilk test. The Student's t-test (normally distributed data) and Mann-Whitney U test (for non-normal data) were used to compare the two groups. The predictive five variables that are determined to be included in the model are tested with univariate analyses: age at diagnosis, BA-CA ratio, estradiol level, uterine length, ovarian volume and pLH level. The ones that are found to be statistically significant are put into multivariate analyses model. Variables that had higher than $70 \%$ sensitivity or specificity were selected for inclusion in the scoring model. Basal LH was not included in scoring system due to being prepubertal level, in generally. Cut-off values for all the predictive variables were determined by using receiver operating characteristic curve (ROC) analysis. A logistic regression model was used to calculate beta coefficients for each variable included in the scoring model. Beta coefficients were calculated for each variable included in the scoring model. Multicollinearity was checked by calculating variance inflation factors. Finally, cut-off values for total scores were determined by a ROC curve analysis. The total score was 12 points. The score of 5 or above points were accepted as PP diagnosis. This model was prospectively applied to a second cohort group in 2014 - 2015.

All univariate analyses were performed in SPSS for Windows, version 22 (IBM). A two sided P value $<0.05$ was defined as statistically significant.

\section{Results}

In this study, 164 (61.5\%) girls were diagnosed with PP and 103 (38.5\%) girls were diagnosed with PT according to conventional diagnostic procedure, retrospectively. The mean age of the patients in the PP and PT groups at onset was $7.21 \pm 1.36$ and $5.09 \pm 2.64$ years, respectively (Table 1). One hundred and seventy-four (66.3\%) girls were in the grey zone. The mean follow-up time was $7.8 \pm 0.07$ months before diagnosis. According to Tanner stage, 134 had B2, 25 had B3 and 5 had B4 grades in PP group. Of PT girls, 92 had B2 and 11 had B3 grades. Seventy-one girls (PP, $n=66$; $\mathrm{PT}, \mathrm{n}=5$ ) showed changes in the pituitary gland on MRI that could not be well defined. We found that following variables were statistically significant to be used in scoring model: Age at diagnosis (years), BA/CA (year), estradiol $(\mathrm{pg} / \mathrm{ml})$, Uterine length $(\mathrm{mm})$ and ovarian volume $\left(\mathrm{cm}^{3}\right)(\mathrm{P}$ $=0.001$ for each variable). Cut off values of variables were determined as follows: Onset age 6.5 years, BA/CA 1.1, estradiol 12pg/ml, uterine length; $32 \mathrm{~mm}$, ovarian volume;1.09 $\mathrm{cm}^{3}$ (Table 2). Beta coefficients for each variable included in scoring model are given in Table 3. Total score obtained from model was 12 points. We calculated the definitive point for each parameter as follows: Onset age 3, BA/CA; 2 , estradiol 3.5, uterine length 2, ovarian volume 1.5 points. Compared to conventional applications (including $\mathrm{GnRH}$ test), the sensitivity and specificity of $M$ was $89.6 \%$ and $87.4 \%$, respectively (Figure 1 ). The accuracy rate of $M$ was $89.8 \%$. The model was applied to a cohort group of 86 girls with early pubertal signs. Table 4 shows diagnostic test results and accuracy rates of the $\mathrm{M}$ in the study and cohort groups.

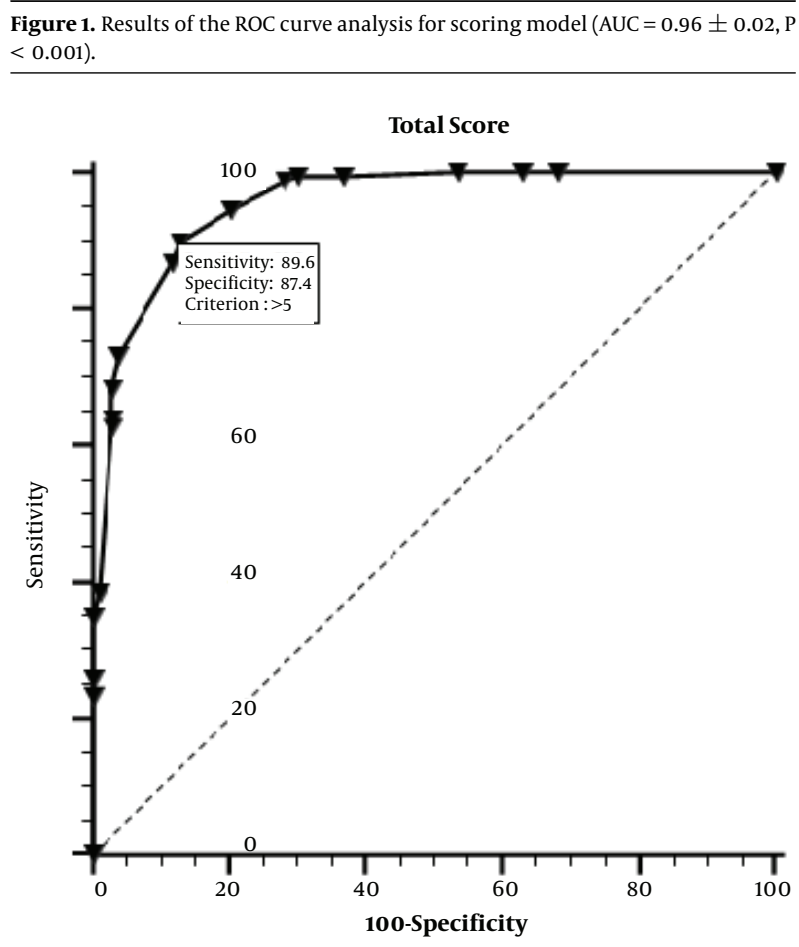

Total score $=12$ points.

\begin{tabular}{|c|c|c|c|}
\hline Variables & $P P(n=164)$ & PT $(n=103)$ & $\mathbf{P}$ \\
\hline Age at diagnosis, year & $7.21 \pm 1.36$ & $5.09 \pm 2.64$ & $0.001^{\mathrm{a}, \mathrm{b}}$ \\
\hline BA/CA, year & $1.91 \pm 1.19$ & $0.37 \pm 0.95$ & $0.001^{a, c}$ \\
\hline Estradiol, pg/ml & $17.4 \pm 5.54$ & $5.99 \pm 3.6$ & $0.001^{a, c}$ \\
\hline Uterine length, mm & $36.77 \pm 7.22$ & $27.43 \pm 6.22$ & $0.001^{a, b}$ \\
\hline Ovarian volume, $\mathrm{cm}^{3}$ & $1.87 \pm 1.03$ & $0.94 \pm 0.80$ & $0.001^{a, c}$ \\
\hline
\end{tabular}


Table 2. Cut Off Values, Specificity and Sensitivity of the Different Variables Included in the Scoring System for PP

\begin{tabular}{lccc}
\hline Variables $^{\mathbf{a}}$ & Cut Off & Sensitivity & Specificity \\
\hline Age at diagnosis, year & $>6.5$ & 86.6 & 57.3 \\
BA/CA, year & $>1.1$ & 70.7 & 86.4 \\
Estradiol, pg/ml & $>12$ & 53 & 94.2 \\
Uterine length, $\mathbf{~ m m}$ & $>32$ & 80.5 & 83.5 \\
\hline Ovarian volume, $\mathbf{c m}^{\mathbf{3}}$ & $>1.09$ & 76.8 & 73.8 \\
\hline
\end{tabular}

${ }^{\mathrm{a}}$ ROC curve analysis.

\section{Discussion}

Distinguishing precocious puberty from premature thelarche sometimes poses diagnostic dilemma. Pubertal signs inconsistent with laboratory findings and multifactorial nature of pubertal onset can cause confusion for clinicians during the decision-making process. Any diagnostic tool cannot allow the definitive diagnosis alone. Although GnRH test is considered as gold standard to make diagnosis, it has some considerable drawbacks $(22,23)$. It is a time consuming, painful and invasive procedure and causes injection anxiety in children. Moreover, its variable sensitivity, specificity and cut off results limit diagnostic value (24).

Scoring models provide estimating simple and useful approach in case of diagnostic equivocal conditions. It is also used to predict prognosis in many diseases (25). Thus, it guides therapeutic process, effectively. In literature, no scoring model has been used in differential diagnosis of precocious puberty, so far.

We aimed to establish a newly scoring model as a complementary or alternative diagnostic approach to GnRH test that distinguishes PP from PT. In this study, we designed that the newly developed scoring system was a reliable method for the differential diagnosis of PP and PT without GnRH test.

In our study, we enrolled 164 (61.5\%) girls who were diagnosed with PP and 103 (38.5\%) girls who were diagnosed with PT according to conventional diagnostic procedures including GnRH test, retrospectively. Age at presentation of pubertal signs is very important in distinguishing between benign early pubertal conditions and true PP (26). Since age at onset of pubertal signs had high sensitivity in our study, we included age at onset in the scoring model. The mean age of the patients in the PP and PT groups at onset was $7.21 \pm 1.36$ and $5.09 \pm 2.64$ years, respectively (Table 1). One hundred and seventy-four (66.3\%) girls were in the grey zone. When compared to previous studies, mean age of our cases was found mildly higher than that in similar reports $(26,27)$. Most of our cases were in grey zone including ages of 7 - 8 years. Later we interpreted that these cases applied to early pubertal signs. Therefore, we couldn't follow growth rate of most cases.

The enlarged uterine length, increased ovarian volume and advanced bone age usually represent the exposure to estrogenic effects due to activation of hypothalamohypophysial-gonadal axis or its excessive peripheral production. These findings indicate reliable evidence of pubertal signs. It was shown in many reports that both increased uterine length and increased ovarian volume can be used to distinguish PP from PT and its variants (28). However, some studies also measured other parameters such as shape, thickness and volume of uterine, the uterine length was used as diagnostic parameter in the present study because it is measured easier (29). We found that cut off value of uterine length is $32 \mathrm{~mm}$ (sensitivity $80.5 \%$ and specificity $83.5 \%$ ). In our study we measured ovarian volume and used mean volume of bilateral ovaries. We calculated that cut off value of ovarian volume is $1.09 \mathrm{~cm}^{3}$ (sensitivity, $76.8 \%$ and specificity, $73.8 \%$ ). There are different measurements for uterine length and ovarian volume as pubertal signs in the literature $(30,31)$. These differences may result from different onset age, duration and stages of pubertal status.

Advanced bone age guides to make diagnosis and predict prognosis in precocious puberty. It also plays a role in making-decision for treatment. Moreover, in a study, it was demonstrated that advanced bone age is the most effective predictor of the result of GnRH test (32). This indicates that advanced bone age can be used as an alternative diagnostic tool to GnRH test. We found that cut off value of bone age to chronological age is 1.1 (sensitivity $70.7 \%$ and specificity $86.4 \%$ ). This measurement is consistent with similar studies (33).

In present study, mean estradiol level $(\mathrm{pg} / \mathrm{ml})$ in PP (mean $17.4 \pm 5.54$ ) was higher than in PT (mean $5.99 \pm$ 3.6) $(\mathrm{P}=0.001)$. Its cut off value was $12 \mathrm{pg} / \mathrm{ml}$ found to use for scoring model. In our scoring model, esradiol had the highest point (3.5 point). This result suggests that level of estrogenic exposure is important and plays a role in development of pubertal changes (34).

Our scoring model is the first report that establishes differential diagnosis of precocious puberty. Therefore, we couldn't compare it with similar studies. We compared with other diagnostic or prognostic scoring models regarding it diagnostic value. There are many clinical scoring models $(35,36)$. Compared with previous scoring models, such as scoring system to distinguish uncomplicated from complicated acute appendicitis, our models have similar diagnostic value (37). Scoring models can be created with combination of many variables (25). The following variables were statistically significant to be used in scoring model: age at diagnosis (years), BA/CA (year), 


\begin{tabular}{|c|c|c|c|c|}
\hline \multirow[b]{2}{*}{ Variables } & \multicolumn{4}{|c|}{ Model: Nagelkerke's $\mathbf{R}^{2}=0.77$ (Sensitivity, 89.6; Specificity, 87.4) } \\
\hline & $\beta$ & Rounded Score & Adjusted OR [95\%Cl] & $\mathbf{P}$ \\
\hline Age at diagnosis & 3.02 & 3 & $20.4[5.87-70.90]$ & $0.001^{\mathrm{a}}$ \\
\hline BA/CA & 2.15 & 2 & $8.61[3.34-22.22]$ & $0.001^{\mathrm{a}}$ \\
\hline Estradiol & 3.63 & 3.5 & $37.64[9.33-151.9]$ & $0.001^{\mathrm{a}}$ \\
\hline Uterine length & 1.89 & 2 & $6.65[2.75-16.12]$ & $0.001^{\mathrm{a}}$ \\
\hline \multirow[t]{2}{*}{ Ovarian volume } & 1.54 & 1.5 & $4.64[1.89-11.35]$ & $0.001^{\mathrm{a}}$ \\
\hline & \multicolumn{4}{|c|}{ Total: 12} \\
\hline
\end{tabular}

${ }^{\mathrm{a}}$ Significant at 0.05 level; Multivariate binary logistic regression analysis.

\begin{tabular}{lcc}
\hline $\begin{array}{l}\text { Table 4. Sensitivity, Specificity and Accuracy Rates for PP Diagnosis in the Study and } \\
\text { Cohort Groups }\end{array}$ \\
\hline Group & $\begin{array}{c}\text { Study Group }(\mathbf{n}=\mathbf{2 6 7})(\mathbf{P P}, \\
\mathbf{n = 1 6 4} \text {; PT, } \mathbf{n}=\mathbf{1 0 3})\end{array}$ & $\begin{array}{c}\text { Cohort Group }(\mathbf{n}=\mathbf{8 6}) \\
(\mathbf{P P}, \mathbf{n}=\mathbf{1 0} \text {; PT, } \mathbf{n}=\mathbf{7 6})\end{array}$ \\
\hline Model cut-off & M Total score $>5(\%)$ & M Total score $>5(\%)$ \\
\hline Sensitivity & 89.6 & 90 \\
\hline Specificity & 87.4 & 89.4 \\
\hline PPV & 91.8 & 53 \\
\hline NPV & 84.1 & 98.5 \\
\hline Accuracy rate & 89.8 & 90.5 \\
\hline
\end{tabular}

estradiol $(\mathrm{pg} / \mathrm{ml})$, uterine length $(\mathrm{mm})$ and ovarian volume $\left(\mathrm{cm}^{3}\right)(\mathrm{P}=0.001$ for each variable). We chose diagnostic variables with both significant and non-invasive diagnostic parameters. These variables are noninvasive measurements except estradiol assay. The sensitivity and specificity of our scoring model was $89.6 \%$ and $87.4 \%$, and its accuracy rate was $89.8 \%$. According to a previous research, the sensitivity and specificity of the GnRH test was $74-100 \%$ using a cut-off pLH level of $5 \mathrm{IU} / \mathrm{L}(4)$. In our cases, the cut-off value for $\mathrm{PLH}$ was $4.37 \mathrm{IU} / \mathrm{L}$, and the sensitivity and specificity of pLH was $79.6 \%$ and $74 \%$, respectively (Table 1). In this study, the sensitivity and specificity values of model were higher than those for the GnRH test. Thus, this new scoring system, which does not rely on the GnRH test, had high sensitivity, specificity and accuracy rates. We believe that this system could be a complementary diagnostic tool or an alternative to the GnRH test in case of diagnostic challenges. Despite that the new scoring system too uses blood test, it has not the disadvantages of GnRH test which is time consuming, expensive and uncomfortable.

Although the specificity of growth velocity was high (90\%), its sensitivity was low (37\%) for PP (2). In our study, most of the girls referred with early pubertal signs were in the grey zone. The diagnostic challenges are the most common in this period. Moreover, we had not time long enough to follow patients' growth velocities due to health insurance payment instructions. As the scoring system does not include growth velocity, it can also be applied as a diagnostic tool in girls for whom growth history data are unavailable. In addition, it can be a useful alternative in patients in whom the GnRH test cannot be performed in practice. Because the scoring system is based mostly on clinical findings, it provides a faster diagnosis, non-invasive and more cost-effective approach than the GnRH test.

The first part of our study was retrospective, and we selected conventional diagnostic variables. The accuracy of the scoring system could be increased by including other significant findings, such as the results of pituitary gland MRI. We suggest that country-specific scoring systems need to be developed. Our study is the first to develop a scoring system for PP. The findings could not be compared with those in the literature due to absence of similar studies. However, our results were compatible with findings reported in studies of scoring systems of different diseases $(12,13)$.

We applied the constructed model to a second cohort group, which consisted of girls who were referred with early pubertal signs. The sensitivity and specificity of $M$ in this cohort group was $90 \%$ and $89.4 \%$, respectively, and its PPV was 53\%. In the cohort group, PPV was not as high as in the study group. We attributed this finding to the small size of the study population (PP $n=10, P T n=7)$. The GnRH test was performed in all the girls in the cohort group.

One of the limitations of this study (first part) is that data was collected retrospectively. The number of cases that we could not reach their records could affect results. Second limitation is that it was a single-center study.Therefore, this first scoring model must be approved by multicenter trials. Another limitation is borderline scores. Using this system, patients with borderline scores (total score of 5 points in M) are considered to have PT. This may pose a diagnostic challenge. In such cases, we recommend taking advanced bone age into account. 


\subsection{Conclusions}

The proposed diagnostic scoring system based on clinical and laboratory findings offers a standard, cost-effective and simple approach to the differential diagnosis of PP, PT and its variants. It also eliminates some disadvantages of the GnRH test and may serve as an alternative or complementary tool for use in the differential diagnosis of PP.

\section{References}

1. Sorensen K, Mouritsen A, Aksglaede L, Hagen CP, Mogensen SS, Juul A. Recent secular trends in pubertal timing: implications for evaluation and diagnosis of precocious puberty. Horm Res Paediatr. 2012;77(3):13745. doi: 10.1159/000336325. [PubMed: 22508036].

2. Pescovitz OH, Hench KD, Barnes KM, Loriaux DL, Cutler GJ. Premature thelarche and central precocious puberty: the relationship between clinical presentation and the gonadotropin response to luteinizing hormone-releasing hormone. J Clin Endocrinol Metab. 1988;67(3):4749. doi: 10.1210/jcem-67-3-474. [PubMed: 3137242].

3. Nam HK, Rhie YJ, Son CS, Park SH, Lee KH. Factors to predict positive results of gonadotropin releasing hormone stimulation test in girls with suspected precocious puberty. J Korean Med Sci. 2012;27(2):1949. doi: 10.3346/jkms.2012.27.2.194. [PubMed: 22323868]. [PubMed Central: PMC3271294].

4. Kim HK, Kee SJ, Seo JY, Yang EM, Chae HJ, Kim CJ. Gonadotropinreleasing hormone stimulation test for precocious puberty. Korean J Lab Med. 2011;31(4):244-9. doi: 10.3343/kjlm.2011.31.4.244. [PubMed: 22016677]. [PubMed Central: PMC3190002].

5. Prasad HK, Khadilkar VV, Jahagirdar R, Khadilkar AV, Lalwani SK Evaluation of GnRH analogue testing in diagnosis and management of children with pubertal disorders. Indian J Endocrinol Metab. 2012;16(3):400-5. doi: 10.4103/2230-8210.95682. [PubMed: 22629507]. [PubMed Central: PMC3354848]

6. Stanhope R, Abdulwahid NA, Adams J, Brook CGD. Studies of gonadotrophin pulsatility and pelvic ultrasound examinations distinguish between isolated premature thelarche and central precocious puberty. Eur J Pediatric. 1986;145:190-4.

7. de Vries L, Guz-Mark A, Lazar L, Reches A, Phillip M. Premature thelarche: age at presentation affects clinical course but not clinical characteristics or risk to progress to precocious puberty. $J$ Pediatr. 2010;156(3):466-71. doi: 10.1016/j.jpeds.2009.09.071. [PubMed: 19914634].

8. Chae HS, Rheu CH. Precocious pseudopuberty due to an autonomous ovarian follicular cyst: case report with a review of literatures. BMC Res Notes. 2013;6:319. doi: 10.1186/1756-0500-6-319. [PubMed: 23937919]. [PubMed Central: PMC3766658].

9. Berberoglu M. Precocious puberty and normal variant puberty: definition, etiology, diagnosis and current management. J Clin Res Pediatr Endocrinol. 2009;1(4):164-74. doi: 10.4274/jcrpe.v1i4.3. [PubMed: 21274291]. [PubMed Central: PMC3005651].

10. de Vries L, Horev G, Schwartz M, Phillip M. Ultrasonographic and clinical parameters for early differentiation between precocious puberty and premature thelarche. Eur J Endocrinol. 2006;154(6):891-8. doi: 10.1530/eje.1.02151. [PubMed: 16728550].

11. Badouraki M, Christoforidis A, Economou I, Dimitriadis AS, Katzos G. Evaluation of pelvic ultrasonography in the diagnosis and differentiation of various forms of sexual precocity in girls. Ultrasound Obstet Gynecol.2008;32(6):819-27. doi:10.1002/uog.6148. [PubMed:18951545].

12. Jawaid A, Asad A, Motiei A, Munir A, Bhutto E, Choudry H, et al. Clinical scoring system: a valuable tool for decision making in cases of acute appendicitis. J Pak Med Assoc. 1999;49(10):254-9. [PubMed: 10647233].
13. Seymour DG, Green M, Vaz FG. Making better decisions: construction of clinical scoring systems by the Spiegelhalter-Knill-Jones approach. BMJ.1990;300(6719):223-6. [PubMed: 2106929]. [PubMed Central: PMC1662045].

14. Gunoz H, Bundak R, Furman A, Darendeliler F, Saka N, Bas F, et al. Z-score reference values for height in Turkish children aged 6 to 18 years. J Clin Res Pediatr Endocrinol. 2014;6(1):28-33. doi: 10.4274/Jcrpe.1260. [PubMed: 24637307]. [PubMed Central: PMC3986736].

15. Neyzi O, Günöz H, Furman A. Türk çocuklarınd a vücut ağırlığı, boy uzunluğu, baş çevresi ve vücut kitle index referans değerleri. Çocuk Sağlı̆̆ ve Hastallkları Dergisi. 2008;51:1-14. Turkish.

16. Kaplowitz P. Clinical characteristics of 104 children referred for evaluation of precocious puberty.JClin Endocrinol Metab. 2004;89(8):364450. doi: 10.1210/jc.2003-031532. [PubMed: 15292280].

17. Neely EK, Wilson DM, Lee PA. Spontaneous serum gonadotropin concentrations in the evaluation of precocious puberty. J Pediatr. 1995;127:47-52.

18. Mogensen SS, Aksglaede L, Mouritsen A, Sorensen K, Main KM, Gideon $P$, et al. Diagnostic work-up of 449 consecutive girls who were referred to be evaluated for precocious puberty. J Clin Endocrinol Metab. 2011;96(5):1393-401. doi: 10.1210/jc.2010-2745. [PubMed: 21346077].

19. Sultan C, Gaspari L, Kalfa N, Paris F. Clinical expression of precocious puberty in girls. Endocr Dev. 2012;22:84-100. doi: 10.1159/000334304. [PubMed: 22846523].

20. Lee PA. Laboratory monitoring of children with precocious puberty. Arch Pediar Adolesc Med.1994;148:369-76.

21. Ozturk A, Mazicioglu MM, Hatipoglu N. Reference body mass index curves for Turkish children 6 to 18 years of age. J Pediatr Endocrinol Metab. 2008;2:827-36.

22. Suh J, Choi MH, Kwon AR, Kim YJ, Jeong JW, Ahn JM, et al. Factors that predict a positive response on gonadotropin-releasing hormone stimulation test for diagnosing central precocious puberty in girls. Ann Pediatr Endocrinol Metab. 2013;18(4):202-7. doi: 10.6065/apem.2013.18.4.202. [PubMed: 24904878]. [PubMed Central: PMC4027085].

23. Resende EA, Lara BH, Reis JD, Ferreira BP, Pereira GA, Borges MF. Assessment of basal and gonadotropin-releasing hormonestimulated gonadotropins by immunochemiluminometric and immunofluorometric assays in normal children. J Clin Endocrinol Metab. 2007;92(4):1424-9. doi: 10.1210/jc.2006-1569. [PubMed: 17284632].

24. Bizzarri C, Spadoni GL, Bottaro G, Montanari G, Giannone G, Cappa $\mathrm{M}$, et al. The response to gonadotropin releasing hormone ( $\mathrm{GnRH}$ ) stimulation test does not predict the progression to true precocious puberty in girls with onset of premature thelarche in the first three years of life. J Clin Endocrinol Metab. 2014;99(2):433-9. doi: 10.1210/jc.2013-3292. [PubMed: 24297793].

25. Hendriksen JM, Geersing GJ, Moons KG, de Groot JA. Diagnostic and prognostic prediction models. J Thromb Haemost. 2013;11 Suppl 1:12941. doi: 10.1111/jth.12262. [PubMed: 23809117].

26. Kilic A, Durmus MS, Unuvar E, Yildiz I, Aydin BK, Ucar A, et al. Clinical and laboratory characteristics of children referred for early puberty: preponderance in 7-8 years of age. J Clin Res Pediatr Endocrinol. 2012;4(4):208-12. doi: 10.4274/jcrpe.736. [PubMed: 23261863]. [PubMed Central: PMC3537288].

27. Di Blasi CC, Roth C, Elfers CT. Is Intermediate Thelarche a New Entity Following a Different Clinical Course Than Premature Thelarche and Central Precocious Puberty? Endocrine Soci 94th Annual Meet Expo. 2012:23-26.

28. Haber HP, Wollmann HA, Ranke MB. Pelvic ultrasonography: early differentiation between isolated premature thelarche and central precocious puberty. Eur J Pediatr. 1995;154(3):182-6. [PubMed: 7758513].

29. Herter LD, Golendziner E, Flores JA. Ovarian and uterine findings in pelvic sonography: comparison between prepubertal girls, girls with isolated thelarche, and girls with central precocious puberty. J Ultrasound Med. 2002;21:1237-46. 
30. Mazgaj M. Sonography of abdominal organs in precocious puberty in girls. J Ultrason. 2013;13(55):418-24. doi: 10.15557/JoU.2013.0044. [PubMed: 26673282]. [PubMed Central: PMC4579676].

31. Lee SH, Joo EY, Lee JE, Jun YH, Kim MY. The Diagnostic Value of Pelvic Ultrasound in Girls with Central Precocious Puberty. Chonnam Med J. 2016;52(1):70-4. doi: 10.4068/cmj.2016.52.1.70. [PubMed: 26866003]. [PubMed Central: PMC4742613].

32. Xu YQ, Li GM, Li Y. Advanced bone age as an indicator facilitates the diagnosis of precocious puberty.J Pediatr (Rio J). 2018;94(1):69-75. doi: 10.1016/j.jped.2017.03.010. [PubMed: 28866322].

33. Yoon SA, Han HS, Kim H, Yun SC. Different clinical courses of central precocious girls according to their age at presentation and treatment. Ann Pediatr Endocrinol Metab. 2013;18(1):19-25. doi: 10.6065/apem.2013.18.1.19. [PubMed: 24904846]. [PubMed Central: PMC4027069].

34. Jenner MR, Kelch RP, Kaplan SL, Grumbach MM. Hormonal changes in puberty. IV. Plasma estradiol, LH, and FSH in prepubertal children, pubertal females, and in precocious puberty, premature thelarche, hypogonadism, and in a child with a feminizing ovarian tumor.JClin Endocrinol Metab. 1972;34(3):521-30. doi: 10.1210/jcem-34-3-521. [PubMed: 5011256].

35. Pruksakorn D, Phanphaisarn A, Settakorn J, Arpornchayanon U, Tantraworasin A, Chaiyawat P, et al. Prognostic score for life expectancy evaluation of lung cancer patients after bone metastasis. J Bone Oncol. 2018;10:1-5. doi: 10.1016/j.jbo.2017.10.001. [PubMed: 29321965]. [PubMed Central: PMC5726457].

36. Sheldon R. Syncope diagnostic scores. Prog Cardiovasc Dis. 2013;55(4):390-5. doi: 10.1016/j.pcad.2012.10.011. [PubMed: 23472776].

37. Atema JJ, van Rossem CC, Leeuwenburgh MM, Stoker J, Boermeester MA. Scoring system to distinguish uncomplicated from complicated acute appendicitis. BrJSurg. 2015;102(8):979-90. doi: 10.1002/bjs.9835. [PubMed: 25963411]. 